\title{
Reading level attenuates differences in neuropsychological test performance between African American and White elders
}

\author{
JENNIFER J. MANLY, ${ }^{1,2,3}$ DIANE M. JACOBS,${ }^{2,3}$ PEGAH TOURADJI, ${ }^{3}$ SCOTT A. SMALL, ${ }^{1,2,3}$ \\ AND YAAKOV STERN ${ }^{1,2,3,4}$ \\ ${ }^{1}$ Cognitive Neuroscience Division, Taub Institute for Research on Alzheimer's Disease and the Aging Brain, \\ Columbia University College of Physicians and Surgeons, New York, NY \\ ${ }^{2}$ Department of Neurology, Columbia University College of Physicians and Surgeons, New York, NY \\ ${ }^{3}$ G.H. Sergievsky Center, Columbia University College of Physicians and Surgeons, New York, NY \\ ${ }^{4}$ Department of Psychiatry, Columbia University College of Physicians and Surgeons, New York, NY \\ (Received March 6, 2001; Revised August 20, 2001; Accepted August 21, 2001)
}

\begin{abstract}
The current study sought to determine if discrepancies in quality of education could explain differences in cognitive test scores between African American and White elders matched on years of education. A comprehensive neuropsychological battery was administered to a sample of African American and non-Hispanic White participants in an epidemiological study of normal aging and dementia in the Northern Manhattan community. All participants were diagnosed as nondemented by a neurologist, and had no history of Parkinson's disease, stroke, mental illness, or head injury. The Reading Recognition subtest from the Wide Range Achievement Test-Version 3 was used as an estimate of quality of education. A MANOVA revealed that African American elders obtained significantly lower scores than Whites on measures of word list learning and memory, figure memory, abstract reasoning, fluency, and visuospatial skill even though the groups were matched on years of education. However, after adjusting the scores for WRAT-3 reading score, the overall effect of race was greatly reduced and racial differences on all tests (except category fluency and a drawing measure) became nonsignificant. These findings suggest that years of education is an inadequate measure of the educational experience among multicultural elders, and that adjusting for quality of education may improve the specificity of certain neuropsychological measures.

(JINS, 2002, 8, 341-348.)
\end{abstract}

Keywords: Quality of education, Racial differences

\section{INTRODUCTION}

Previous research on cognitive test performance of African Americans has compared African Americans to Whites on intelligence tests (Chen et al., 1994; Heaton et al., 1996; Kaufman et al., 1988; Kush \& Watkins, 1997; Overall \& Levin, 1978; Reynolds et al., 1987; Vincent, 1991) and screening measures (Bohnstedt et al., 1994; Fillenbaum et al., 1988, 1990; Ford et al., 1996; Kuller et al., 1998; Murden et al., 1991; Teresi et al., 1995; Unverzagt et al., 1996; Welsh et al., 1995). Prior research has also investigated

Reprint requests to: Jennifer Manly, Ph.D., G.H. Sergievsky Center, 630 West 168th Street P \& S Box 16, New York, NY 10032. E-mail: jjm71@columbia.edu performance of African Americans on neuropsychological tests of naming (Lichtenberg et al., 1994; Roberts \& Hamsher, 1984; Ross et al., 1995), reading (Boekamp et al., 1995), nonverbal abilities (Adams et al., 1982; Anger et al., 1997; Bernard, 1989; Brown et al., 1991; Campbell et al., 1996; Heverly et al., 1986; Miller et al., 1993), and dementia batteries (Carlson et al., 1998; Inouye et al., 1993; Manly et al., 1998a; Marcopulos et al., 1997; Ripich et al., 1997; Unverzagt et al., 1996; Welsh et al., 1995). These racial comparisons have generally shown that despite equivalence on demographic variables such as years of education and socioeconomic status, African Americans obtain lower scores on both verbal and nonverbal cognitive tasks. These discrepancies cause attenuated specificity, such that cognitively normal African Americans are more likely to be mis- 
diagnosed as impaired as compared to Whites (FordBooker et al., 1993; Klusman et al., 1991; Manly et al., 1998a, 1998b, 1998c; Stern et al., 1992; Welsh et al., 1995).

In each of these studies, investigators used covariance or matching procedures in order to equate racial groups on years of education before comparing neuropsychological test performance, since education often differs in groups of African Americans and Whites. Therefore, these findings depend on whether we can successfully adjust for years of education. However, along with several other authors (Kaufman et al., 1997; Loewenstein et al., 1994; Whitfield \& Baker-Thomas, 1999), we argue that matching on quantity of formal education does not necessarily mean that the quality of education received by each racial group is comparable. There is abundant evidence to suggest that years of education is not commensurate between African Americans and Whites and is thus an inadequate estimate of educational experience.

In the United States there is a great deal of discordance between years of education and quality of education; this is especially true among African American elders. Previous studies reveal that African Americans have reading skills significantly below their self-reported education level (Albert \& Teresi, 1999; Baker et al., 1996). African Americans educated in the South before the Supreme Court's 1954 Brown v. Board of Education decision attended segregated schools, which received inferior funding as compared to White Southern schools and most integrated Northern schools (Anderson, 1988). Beginning with the Coleman report (Coleman, 1966), several researchers have demonstrated that school characteristics such as pupil expenditures, teacher quality, pupil/teacher ratios, presence of special facilities such as science laboratories, length of school year/ days attended, and peer characteristics were able to account for much of the difference in achievement and other outcomes (e.g., wage earnings), between African Americans and Whites (Hanushek, 1989; Hedges et al., 1994; O'Neill, 1990). The unequal distribution of funds to segregated African American schools in the South in the first half of this century, and the subsequent lower quality of education, was related to lower earnings among African Americans in a number of studies (Margo, 1985; 1990; Smith, 1984; Smith \& Welch, 1977; Welch, 1966; 1973). African American children were often employed or used as labor during the harvest, which reduced attendance during the year. This gap in days attended also contributes to differences in quality of education and literacy levels per year in school (Margo, 1985).

In summary, the variable years of education systematically differs between racial groups and is also related to cognitive test performance. If this variable is not commensurate between racial groups, residual confounding will occur and spurious racial differences will be interpreted despite matching groups on years of education. Disparate school experiences, and thus different bases of problem-solving strategies, knowledge, familiarity, and practice could explain why some African Americans obtain lower scores on cognitive measures even after matching groups on years of education. Statistical control of years of education may be inadequate or inappropriate since different scales of measurement are being used between (and within) each racial group (Kaufman et al., 1997; Loewenstein et al., 1994).

Measures of reading achievement correlate with overall academic achievement (Wilkinson, 1993) and with direct measures of quality of education such as pupil expenditures, teacher/student ratios, and teacher education (Hedges et al., 1994). The current study uses the Reading Recognition subtest from the WRAT-3 as an estimate of quality of education, since this measure and other WRAT scores have been found to remain relatively stable over time (Johnstone \& Wilhelm, 1996; Wilkinson, 1993).

If the WRAT-3 is used as an estimate of quality of education, it may be important to assure that any correlation between reading score and neuropsychological test performance is independent of variance that might be shared due to the fact that they are both tests. In other words, racial group differences may simply reflect a higher level of "testwiseness" among non-Hispanic Whites rather than discrepancies in quality of education. Test-wiseness is defined as the ability to use the format and characteristics of a test to achieve a high score (Scruggs \& Lifson, 1985), and the use of deduction and item cues to answer questions (Borrello \& Thompson, 1985). Test-wiseness has traditionally been measured using multiple-choice items that can only be answered correctly using secondary cues irrelevant to item content.

The purpose of this study was to determine if discrepancies in quality of education could explain differences in cognitive test score between African American and White elders matched on years of education. We hypothesized that we would find significant racial differences on measures of figure memory, verbal abstraction, fluency, and visuospatial skill, but that these differences would be significantly reduced after accounting for our best estimate of quality of education (reading level). We hypothesized that the effect of race would persist after adjusting for an estimate of testwiseness and that reading level would continue to reduce the effect of race after accounting for test-wiseness.

\section{METHODS}

\section{Research Participants}

The current sample was selected from participants in the Washington Heights-Inwood Columbia Aging Project (WHICAP), a community-based, epidemiological study of dementia in the ethnically diverse neighborhoods of Northern Manhattan, New York. The WHICAP study follows a random sample of elderly Medicare recipients residing in selected census tracts of Washington Heights and Inwood.

\section{Inclusion/exclusion criteria}

All potential participants were age 65 and above and performed the neuropsychological battery in English. Partici- 
pants were included if they self-identified their race as White or Black/African American and their "ethnicity" as nonHispanic according to US Census Criteria (United States Bureau of the Census, 1991). Participants were asked to categorize how well they spoke English: very well; well; or not well. The current study included only those participants who said they spoke English very well. Potential participants were excluded if they had a history of Parkinson's disease, stroke, head injury with loss of consciousness, alcohol abuse, or serious mental illness such as depression or schizophrenia. Only WHICAP participants who showed no neurological or functional signs of dementia were included in the current analyses. This determination was made on the basis of a physician's clinical examination, which included a rating of daily functioning (see procedures below). The physician's diagnosis was used as a gold standard for the absence of dementia, since the neurological assessment was made independent of the participant's performance on the neuropsychological battery.

\section{Medical evaluation}

A physician recorded medical history and medications in a semi-structured format. Neurological and brief physical examinations were performed, including assessment of extrapyramidal signs. Functional status was measured using Part 1 of the Blessed Dementia Rating Scale (BDRS; Blessed et al., 1968) and the Schwab and England rating scale of activities of daily living (Boller et al., 1980). From this information, the physician determined whether the participant met criteria for delirium or dementia using Diagnostic and Statistical Manual of Mental Disorders-Revised Third Edition (American Psychiatric Association, 1987) criteria.

\section{Procedure}

\section{Neuropsychological battery}

The neuropsychological measures used in the current study were selected to assess cognitive functions that are typically affected in dementia and have been shown to effectively distinguish between normal aging and dementia in this community (Stern et al., 1992). The evaluation included measures of learning and memory, orientation, abstract reasoning, language, and visuospatial ability. Specific ability areas and tests administered include verbal list learning and memory [Selective Reminding Test (SRT); Buschke \& Fuld, 1974], nonverbal memory [multiple choice version of the Benton Visual Retention Test (BVRT); Benton, 1955], orientation [items from the Mini Mental State Examination (MMSE); Folstein et al., 1975], verbal reasoning [Similarities subtest of the Wechsler Adult Intelligence Scale-Revised (WAIS-R); Wechsler, 1981], nonverbal reasoning (Identities and Oddities subtest of the Mattis Dementia Rating Scale; Mattis, 1976), naming (15-item version of the Boston Naming Test; Kaplan et al., 1983), letter fluency (Controlled Word Association; Benton \& Hamsher,
1976), category fluency [animals, food, and clothing, using procedures from the Boston Diagnostic Aphasia Examination (BDAE); Goodglass \& Kaplan, 1983], repetition (highfrequency phrases of the BDAE; Goodglass \& Kaplan, 1983), auditory comprehension (first six items of the Complex Ideational Material subtest of the BDAE; Goodglass \& Kaplan, 1983), visuoconstruction (Rosen Drawing Test; Rosen, 1981), and visuoperceptual skills (multiple choice matching of figures from the BVRT; Benton, 1955).

\section{Reading level}

Reading level was measured using the Reading Recognition subtest from the Wide Range Achievement TestVersion 3 (Wilkinson, 1993). Participants were asked to name letters and pronounce words out of context. The words are listed in order of decreasing familiarity and increasing phonological complexity. Consistent with the standard instructions for administration, a basal of 5 correct and a ceiling of 10 incorrect was used. WRAT -3 grade equivalent scores were derived from the normative values for people age 70 to 75 years from the manual.

\section{Test-wiseness}

Word Recognition score from the Selective Reminding Test (SRT) was used as an estimate of test-wiseness. SRT Word Recognition requires the participant to select previously presented words from four-choice multiple-choice arrays. Distractors are both phonemic and semantic in nature (e.g., correct choice $=$ helmet , distractors $=$ armor, velvet, bacon $)$.

\section{Statistical Methods}

In order to create groups matched on years of education and sex, a stratified random sampling method was applied. The sample was stratified by race (White, African American), sex (male, female) and four categories based on years of education (0-8; 9-11; 12-15; and greater than 16 years). Within each Education $\times$ Race $\times$ Sex cell, a random sample of subjects was selected using the SPSS (1998) sample function. Equal numbers of participants were selected within each Education $\times$ Race $\times$ Sex stratum.

Chi-square tests were used to compare African Americans and Whites on estimated grade level based on their WRAT-3 reading performance, and $t$ tests were used to compare raw WRAT scores by race.

A MANOVA was used to compare African Americans and Whites on the overall test battery. Thirteen measures from the test battery were included as dependent variables: total raw scores for immediate recall and delayed recall from the SRT; BVRT matching and recognition memory; items correct on the MMSE Orientation; 15-item Boston Naming; BDAE repetition; BDAE comprehension; Mattis Identities and Oddities; number correct on the Rosen Drawing Test; raw score on WAIS-R Similarities; and mean number of words generated over three 60-s trials for category and letter fluency. Post-hoc ANOVAs were performed to 
determine which specific neuropsychological measures contributed significantly to the overall multivariate effect. In order to strike a balance between the likelihood of committing Type I and Type II errors, an alpha level of $p<.01$ was used to determine statistically significant univariate differences.

WRAT-3 reading score was then added as an additional covariate into a MANCOVA, in order to test the effect of race after adjusting for our estimate of quality of education. Again, an alpha level of $p<.01$ was used to determine statistically significant univariate differences. A final MANCOVA was performed in order to determine if covarying for WRAT-3 score had the same effect on cognitive test differences between African American and Whites after accounting for SRT recognition performance, our estimate of test-wiseness.

\section{RESULTS}

\section{Sample Characteristics}

A total of 708 English-speaking WHICAP participants had complete neuropsychological evaluations, WRAT-3 data, and neurological exams. Of these, 322 identified as nonHispanic White and 386 identified as non-Hispanic Black. After excluding participants who did not meet inclusion/ exclusion criteria, 248 White and 317 African American participants remained.

Whites and African Americans were compared on years of education and age using $t$-tests, and chi-square analysis compared the proportion of women in each racial group. As expected, there was a significant difference in years of education between African Americans $(M=11.0, S D=3.6)$ and Whites $[M=13.8, S D=3.2 ; t(563)=9.4, p<.001]$. There was no age difference between African American $(M=74.5, S D=5.9)$ and White elders $[M=75.0, S D=$ $5.9 ; t(563)=0.05, p=.96]$. The White group was $60 \%$ female, and $76 \%$ of the African American elders were women $\left[\chi^{2}(1, N=565)=18.0, p<.001\right]$. A stratified random sampling method (described above) was then used to match the White and African American participants on years of education and sex.

Groups of 192 African American and 192 White elders matched on educational attainment and sex distribution were formed through the stratified random sampling procedure. Table 1 compares the demographic characteristics of the two groups. As directed by the matching procedure, both groups were $68 \%$ female, and there was no significant difference in years of education between African Americans and Whites. There was still no age difference between the groups.

\section{Race, Reading Level, and Neuropsychological Test Performance}

As expected, there was a significant difference in WRAT-3 reading scores between racial groups (Table 1). When raw WRAT-3 scores were converted into grade-equivalent scores and compared with reported years of education, selfreported years of education was an overestimate of actual reading level for a higher proportion of African Americans (33\%) than Whites $(7 \%)$.

A MANCOVA revealed that African Americans scored significantly lower on the neuropsychological test battery overall as compared to Whites $[F(13,370)=6.2, p<.001]$. Follow-up univariate tests revealed significant differences between African Americans and Whites on measures of word list learning and memory (SRT total immediate and delayed recall), figure memory (BVRT recognition), abstract reasoning (WAIS-R Similarities and DRS identities and oddities), letter fluency, category fluency, and visuospatial skill (Rosen drawings and BVRT matching). Table 2 shows racial group means and standard deviations on each test within the battery.

WRAT-3 scores accounted for $34 \%$ of the variance of test scores overall, which was significant $[F(13,369)=14.3$, $p<.001]$. When WRAT-3 scores were entered into the multivariate model, the overall effect of race remained significant $[F(13,368)=2.7, p=.001]$, but the effect size was significantly reduced. Follow-up univariate comparisons

Table 1. Demographics and reading level for African American and White elders

\begin{tabular}{lcccc}
\hline \hline & $\begin{array}{c}\text { African } \\
\text { American }\end{array}$ & $\begin{array}{c}\text { White } \\
\text { Variable }\end{array}$ & $\begin{array}{c}\text { Statistic } \\
t \text { or } \chi^{2}\end{array}$ & $p$ \\
\hline$N$ & 192 & $192)$ & & \\
$\%$ Female & $68.2 \%$ & $68.2 \%$ & - & - \\
Age & $73.9(5.8)$ & $74.6(5.9)$ & 1.0 & .30 \\
Years of education & $12.8(2.8)$ & $13.0(3.0)$ & .60 & .55 \\
WRAT-3 reading score & $44.2(7.2)$ & $49.3(4.1)$ & 8.4 & $<.001$ \\
Reading level $=$ reported grade & $47 \%$ & $56 \%$ & & \\
Reading level $>$ reported grade & $20 \%$ & $38 \%$ & & \\
Reading level $<$ reported grade & $33 \%$ & $7 \%$ & 48.98 & $<.001$ \\
\hline \hline
\end{tabular}


Table 2. Effect of race and WRAT-3 reading score on neuropsychological test score

\begin{tabular}{|c|c|c|c|c|c|c|}
\hline \multirow[b]{2}{*}{ Test } & \multirow[b]{2}{*}{ African American } & \multirow[b]{2}{*}{ White } & \multicolumn{2}{|c|}{ Effect of race } & \multicolumn{2}{|c|}{$\begin{array}{c}\text { After covarying } \\
\text { for WRAT } \\
\text { reading score }\end{array}$} \\
\hline & & & $F$ & $p$ & $F$ & $p$ \\
\hline \multicolumn{7}{|l|}{ Learning/Memory } \\
\hline SRT total recall & $39.8(10.1)$ & $43.5(10.1)$ & 12.9 & .000 & 1.7 & .194 \\
\hline SRT delayed recall & $5.8 \quad(2.7)$ & $6.7 \quad(2.9)$ & 8.9 & .003 & 0.7 & .407 \\
\hline BVRT recognition memory & 7.4 (1.8) & 8.1 (1.5) & 20.4 & .000 & 2.5 & .115 \\
\hline \multicolumn{7}{|l|}{ Orientation } \\
\hline MMSE orientation & $9.7 \quad(0.7)$ & $9.8 \quad(0.5)$ & 3.5 & .062 & 1.0 & .310 \\
\hline \multicolumn{7}{|l|}{ Abstract reasoning } \\
\hline WAIS-R Similarities raw & $12.0 \quad(6.9)$ & $16.0 \quad(6.3)$ & 34.8 & .000 & 3.7 & .055 \\
\hline DRS Identities \& Oddities & $14.6 \quad(1.7)$ & $15.1 \quad(1.3)$ & 10.8 & .001 & 1.8 & .186 \\
\hline \multicolumn{7}{|l|}{ Language } \\
\hline Boston Naming & 14.0 & 14.1 & 0.5 & .480 & 2.8 & .093 \\
\hline Letter fluency & $9.9 \quad(3.8)$ & $12.2(4.1)$ & 31.8 & .000 & 3.0 & .083 \\
\hline Category fluency & $14.6 \quad(3.8)$ & 16.8 & 31.4 & .000 & 10.0 & .002 \\
\hline BDAE repetition & $7.8 \quad(0.6)$ & $7.8 \quad(0.5)$ & 0.0 & .848 & 1.3 & .250 \\
\hline BDAE comprehension & $5.5(0.9)$ & $5.8(0.7)$ & 13.4 & .000 & 3.2 & .073 \\
\hline \multicolumn{7}{|l|}{ Visuospatial ability } \\
\hline Rosen drawing & $2.6(0.9)$ & $3.0(0.8)$ & 30.0 & .000 & 10.9 & .001 \\
\hline BVRT matching & $8.9(1.4)$ & $9.4 \quad(1.2)$ & 13.1 & .000 & 3.4 & .065 \\
\hline
\end{tabular}

Note. SRT $=$ Selective Reminding Test; BVRT $=$ Benton Visual Retention Test; MMSE $=$ Mini-Mental State Examination; WAIS-R = Wechsler Adult Intelligence Scale-Revised; DRS = Dementia Rating Scale; BDAE = Boston Diagnostic Aphasia Examination.

(Table 2) showed that after accounting for WRAT-3 score, racial differences on all measures except category fluency and the Rosen drawing test were no longer significant.

Next, our best estimate of "test-taking savvy," the SRT Word Recognition task, was added as an predictor of neuropsychological test scores in a multivariate model. SRT Recognition was related to scores on all ten measures except the Rosen drawing test ( $p<.001$ for all); however, even after SRT Recognition was accounted for, there was no change in the overall effect of race on cognitive test score $[F(13,369)=5.7, p<.001]$. When WRAT-3 score was added as a predictor in the model in addition to SRT Recognition score, the effect of race became nonsignificant for all measures except Rosen drawing and category fluency, the same result as when WRAT-3 alone was used as a covariate.

\section{DISCUSSION}

The current study found that accounting for WRAT-3 Reading recognition performance, an estimate of quality of education, attenuates racial group differences on most cognitive tests between African American and White elders matched on years of education. These findings suggest that the full extent of discrepancies in educational experience between African Americans and Whites are not captured by a simple "highest-grade-attained" variable, and thus residual confounding may explain findings of persistent race effects after matching groups on years of education.
Although adjustment for reading recognition accounted for racial differences on the letter fluency task, the effect of race on category fluency remained significant. In addition, WRAT-3 score did not fully account for racial differences in the Rosen drawing task, but discrepancies in figure matching became nonsignificant. In other words, WRAT-3 score was significantly correlated with Rosen drawing and category fluency in both racial groups and accounted for racial differences in related tasks; however, differences in reading level cannot fully explain racial discrepancies on these two measures. It is possible that other cultural differences, unmeasured in this study, can account for racial differences in performance on these two measures. One possible factor is cultural experience, which has been shown to account for some test differences between African American and White HIV-positive individuals (Manly et al., 1998d). It is also possible that WRAT-3 score does not capture the aspects of quality of education that are related to semantic fluency and copying geometric figures. Future study will determine whether variables such as per student costs, teacher salaries, or length of school year can more completely explain discrepancies in test performance between these two racial groups.

Although the utility of single-word reading measures such as the WRAT in premorbid IQ estimation is controversial (Dura et al., 1989; Johnstone et al., 1996; Johnstone \& Wilhelm, 1996; O'Carroll, 1995; Storandt et al., 1995), one longitudinal study of incident dementia (Schmand et al., 1998) concluded that reading level remains a valid estimate 
of premorbid ability in mild and questionable dementia; this is the same context in which the results of this study will be most useful. Certainly, a major limitation of reading recognition scores as an estimate of educational quality is that scores would be inaccurate among elders with history of learning disabilities or severe language disturbance related to a neurological disease.

Educational quality is only one of many variables that may influence reading recognition scores, including general cognitive ability, reading experience obtained through access to books in the home or as a result of occupational demands, and test-wiseness. We attempted to control for one of these factors by determining if reading score attenuated the effect of race after accounting for an estimate of test-wiseness. SRT Word Recognition score was used as an estimate of test-taking ability because it is a multiplechoice task in which participants may use a process of elimination and regularities of distractors to help narrow the field of possible correct answers. This score is certainly not a perfect measure of test-wiseness; rather, its inclusion served to adjust the neuropsychological test scores for shared attributes of all cognitive tasks.

The results of the current study have both practical and conceptual implications. Practically, these findings suggest that race-specific norms which correct for years of education may be less accurate than norms which correct for quality of education and are not specific to one racial classification. Neuropsychologists use demographically corrected norms to improve the accuracy of predictions of a normal individual's performance, and thus improve the specificity and sensitivity of a task to detect cognitive impairment. Just as age and sex are expected to adjust expectations of an individual's performance, years of education has traditionally been used to adjust for changes in baseline knowledge, strategy, and skill that are accompanied by formal schooling. However, this study adds to the multitude of evidence, collected mainly by educational psychologists and economists, that shows racial inequity in the value of any unit of quantity of education. Based on the results of this study, we propose that regardless of race, the WRAT-3 reading test measures educational experience more accurately than years of education, and thus is a superior assessment of the knowledge, strategy, and skills needed to perform well on traditional neuropsychological tasks. Test scores adjusted for reading level can be used to predict performance more accurately than if only years of education and racial classification were used.

The current research approach also addresses the fallacy underlying most comparisons of test performance between African Americans and Whites; the assumption that because racial groups are matched on socioeconomic variables such as years of education, persistent race effects can be interpreted as biologically meaningful. One way to avoid this faulty conclusion is to specify and measure the experiential, attitudinal, or behavioral variables that are expected to distinguish those belonging to different ethnic groups, and which also vary among individuals within an ethnic group (Helms, 1992). These factors may reflect underlying reasons for the relationship between racial classification and cognitive test performance. Because racial differences on cognitive test performance were significantly reduced (and in most cases, eliminated) by accounting for just one indicator of educational quality, the current findings support this approach. This investigational approach may illuminate factors which can explain not only ethnic group differences on cognitive tests, but can inform our future development of measures designed to measure cognitive abilities salient within African American culture. The effect of specific cultural and educational factors on cognitive test performance must be well understood before we attempt to develop culture-fair measures.

\section{ACKNOWLEDGMENTS}

This research was supported by federal grants AG16206 (J. Manly), AG07232 (R. Mayeux), the Alzheimer's Association, and the New York City Speakers Fund for Biomedical Research-Toward the Science of Patient Care. The authors thank Rosann Costa for her help with data management and Maria Gonzalez-Diaz, Cherita McDowell, and Judes Fleurimont for their assistance with scheduling and interviewing participants.

\section{REFERENCES}

Adams, R.L., Boake, C., \& Crain, C. (1982). Bias in a neuropsychological test classification related to age, education and ethnicity. Journal of Consulting and Clinical Psychology, 50, 143-145.

Albert, S.M. \& Teresi, J.A. (1999). Reading ability, education, and cognitive status assessment among older adults in Harlem, New York City. American Journal of Public Health, 89, 95-97.

American Psychiatric Association. (1987). Diagnostic and statistical manual of mental disorders, revised third edition. Washington, DC: American Psychiatric Press Inc.

Anderson, J.D. (1988). The education of Blacks in the South, 1860 1935. Chapel Hill: University of North Carolina Press.

Anger, W.K., Sizemore, O.J., Grossman, S.J., Glasser, J.A., Letz, R., \& Bowler, R. (1997). Human neurobehavioral research methods: Impact of subject variables. Environmental Research, 73, 18-41.

Baker, F.M., Johnson, J.T., Velli, S.A., \& Wiley, C. (1996). Congruence between education and reading levels of older persons. Psychiatric Services, 47, 194-196.

Benton, A.L. (1955). The Visual Retention Test. New York: The Psychological Corporation.

Benton, A.L. \& Hamsher, K. de S. (1976). Multilingual Aphasia Examination. Iowa City: University of Iowa.

Bernard, L. (1989). Halstead-Reitan neuropsychological test performance of Black, Hispanic, and White young adult males from poor academic backgrounds. Archives of Clinical Neuropsychology, 4, 267-274.

Blessed, G., Tomlinson, B.E., \& Roth, M. (1968). The association between quantitative measures of senile change in the cerebral grey matter of elderly subjects. British Journal of Psychology, 114, 797-811.

Boekamp, J.R., Strauss, M.E., \& Adams, N. (1995). Estimating premorbid intelligence in African-American and White elderly 
veterans using the American version of the National Adult Reading Test. Journal of Clinical and Experimental Neuropsychology, 17, 645-653.

Bohnstedt, M., Fox, P.J., \& Kohatsu, N.D. (1994). Correlates of Mini-Mental Status Examination scores among elderly demented patients: The influence of race-ethnicity. Journal of Clinical Epidemiology, 47, 1381-1387.

Boller, F., Mizutani, T., Roessmann, U., \& Gambetti, P. (1980). Parkinson's disease, dementia, and Alzheimer's disease: Clinicopathological correlations. Annals of Neurology, 1, 329-335.

Borrello, G.M. \& Thompson, B. (1985). Correlates of selected test wiseness skills. Journal of Experimental Education, 53, 124-128.

Brown, A., Campbell, A., Wood, D., Hastings, A., Lewis-Jack, O., Dennis, G., Ford-Booker, P., Hicks, L., Adeshoye, A., Weir, R., \& Davis, T. (1991). Neuropsychological studies of Blacks with cerebrovascular disorders: A preliminary investigation. Journal of the National Medical Association, 83, 3-217.

Buschke, H. \& Fuld, P.A. (1974). Evaluating storage, retention, and retrieval in disordered memory and learning. Neurology, 24, 1019-1025.

Campbell, A., Rorie, K., Dennis, G., Wood, D., Combs, S., Hearn, L., Davis, H., Brown, A., \& Weir, R. (1996). Neuropsychological assessment of African Americans: Conceptual and methodological considerations. In R. Jones (Ed.), Handbook of tests and measurement for black populations (Vol. 2, pp. 75-84). Berkeley, CA: Cobb \& Henry.

Carlson, M.C., Brandt, J., Carson, K.A., \& Kawas, C.H. (1998). Lack of relation between race and cognitive test performance in Alzheimer's disease. Neurology, 50, 1499-1501.

Chen, T.-H., Kaufman, A.S., \& Kaufman, J.C. (1994). Examining the interaction of age $\times$ race pertaining to black-white differences at ages 15 to 93 on six Horn abilities assessed by K-FAST, K-SNAP, and KAIT subtests. Perceptual and Motor Skills, 79, 1683-1690.

Coleman, J. (1966). Equality of educational opportunity. Washington, DC: Government Printing Office.

Dura, J.R., Myers, E.G., \& Freathy, D.T. (1989). Stability of the Wide Range Achievement Test in an adolescent psychiatric inpatient setting. Educational and Psychological Measurement, 49, 253-256.

Fillenbaum, G., Heyman, A., Williams, K., Prosnitz, B., \& Burchett, B. (1990). Sensitivity and specificity of standardized screens of cognitive impairment and dementia among elderly black and white community residents. Journal of Clinical Epidemiology, 43, 651-660.

Fillenbaum, G.G., Hughes, D.C., Heyman, A., George, L.K., \& Blazer, D.G. (1988). Relationship of health and demographic characteristics to Mini-Mental State examination score among community residents. Psychological Medicine, 18, 719-726.

Folstein, M.F., Folstein, S.E., \& McHugh, P.R. (1975). 'Minimental State': A practical method for grading the cognitive state of patients for the clinician. Journal of Psychiatric Research, 12, 189-198.

Ford-Booker, P., Campbell, A., Combs, S., Lewis, S., Ocampo, C., Brown, A., Lewis-Jack, O., \& Rorie, K. (1993). The predictive accuracy of neuropsychological tests in a normal population of African Americans. Journal of Clinical and Experimental Neuropsychology, 15, 64.

Ford, G.R., Haley, W.E., Thrower, S.L., West, C.A.C., \& Harrell, L.E. (1996). Utility of Mini-Mental State Exam scores in predicting functional impairment among White and African Amer- ican dementia patients. Journals of Gerontology: Biological Sciences and Medical Sciences, 51, 185-188.

Goodglass, H. \& Kaplan, E. (1983). The assessment of aphasia and related disorders (2nd ed.). Philadelphia: Lea \& Febiger.

Hanushek, E. (1989). The impact of differential expenditures on school performance. Educational Researcher, 18, 45-51.

Heaton, R.K., Ryan, L., Grant, I., \& Matthews, C.G. (1996). Demographic influences on neuropsychological test performance. In I. Grant \& K.M. Adams (Eds.), Neuropsychological assessment of neuropsychiatric disorders (2nd ed.; pp. 141163). New York: Oxford University Press.

Hedges, L.V., Laine, R.D., \& Greenwald, R. (1994). Does money matter? A meta-analysis of studies of the effects of differential school inputs on student outcomes. Educational Researcher, 23, 5-14.

Helms, J.E. (1992). Why is there no study of cultural equivalence in standardized cognitive ability testing? American Psychologist, 47, 1083-1101.

Heverly, L.L., Isaac, W., \& Hynd, G.W. (1986). Neurodevelopmental and racial differences in tactile-visual (cross-modal) discrimination in normal black and white children. Archives of Clinical Neuropsychology, 1, 139-145.

Inouye, S.K., Albert, M.S., Mohs, R., Sun, K., \& Berkman, L.F. (1993). Cognitive performance in a high-functioning community-dwelling elderly population. Journal of Gerontology: Medical Sciences, 48, 146-151.

Johnstone, B., Callahan, C.D., Kapila, C.J., \& Bouman, D.E. (1996). The comparability of the WRAT-R Reading Test and NAART as estimates of premorbid intelligence in neurologically impaired patients. Archives of Clinical Neuropsychology, 11, 513-519.

Johnstone, B. \& Wilhelm, K.L. (1996). The longitudinal stability of the WRAT-R reading subtest: Is it an appropriate estimate of premorbid intelligence? Journal of the International Neuropsychological Society, 2, 282-285.

Kaplan, E., Goodglass, H., \& Weintraub, S. (1983). Boston Naming Test. Philadelphia: Lea \& Febiger.

Kaufman, J.S., Cooper, R.S., \& McGee, D.L. (1997). Socioeconomic status and health in blacks and whites: The problem of residual confounding and the resilience of race. Epidemiology, 8, 621-628.

Kaufman, A.S., McLean, J.E., \& Reynolds, C.R. (1988). Sex, race, residence, region, and education differences on the 11 WAIS-R subtests. Journal of Clinical Psychology, 44, 231-248.

Klusman, L.E., Moulton, J.M., Hornbostle, L.K., Picano, J.J., \& Beattie, M.T. (1991). Neuropsychological abnormalities in asymptomatic HIV seropositive military personnel. Journal of Neuropsychological and Clinical Neurosciences, 3, 422-428.

Kuller, L.H., Shemanski, L., Manolio, T., Haan, M., Fried, L., Bryan, N., Burke, G.L., Tracy, R., \& Bhadelia, R. (1998). Relationship between ApoE, MRI findings, and cognitive function in the Cardiovascular Health Study. Stroke, 29, 388-398.

Kush, J.C. \& Watkins, M.W. (1997). Construct validity of the WISC-III verbal and performance factors for Black special education students. Assessment, 4, 297-304.

Lichtenberg, P.A., Ross, T., \& Christensen, B. (1994). Preliminary normative data on the Boston Naming Test for an older urban population. Clinical Neuropsychologist, 8, 109-111.

Loewenstein, D.A., Arguelles, T., Arguelles, S., \& Linn-Fuentes, P. (1994). Potential cultural bias in the neuropsychological assessment of the older adult. Journal of Clinical and Experimental Neuropsychology, 16, 623-629. 
Manly, J.J., Jacobs, D.M., Sano, M., Bell, K., Merchant, C.A., Small, S.A., \& Stern, Y. (1998a). Cognitive test performance among nondemented elderly African Americans and Whites. Neurology, 50, 1238-1245.

Manly, J.J., Jacobs, D.M., Sano, M., Bell, K., Merchant, C.A., Small, S.A., \& Stern, Y. (1998b). Cross-cultural comparison of neuropsychological test performance and diagnosis of dementia. Neurology, 50, 91.

Manly, J.J., Jacobs, D.M., Sano, M., Bell, K., Merchant, C.A., Small, S.A., \& Stern, Y. (1998c). African American acculturation and neuropsychological test performance among nondemented community elders. Journal of the International Neuropsychological Society, 4, 77.

Manly, J.J., Miller, S.W., Heaton, R.K., Byrd, D., Reilly, J., Velasquez, R.J., Saccuzzo, D.P., Grant, I., \& the HIV Neurobehavioral Research Center Group. (1998d). The effect of AfricanAmerican acculturation on neuropsychological test performance in normal and HIV positive individuals. Journal of the International Neuropsychological Society, 4, 291-302.

Marcopulos, B.A., McLain, C.A., \& Giuliano, A.J. (1997). Cognitive impairment or inadequate norms: A study of healthy, rural, older adults with limited education. Clinical Neuropsychologist, 11, 111-131.

Margo, R.A. (1985). Disenfranchisement, school finance, and the economics of segregated schools in the United States south, 1890-1910. New York: Garland Publishing.

Margo, R.A. (1990). Race and schooling in the South, 1880-1950: An economic history. Chicago: University of Chicago Press.

Mattis, S. (1976). Mental status examination for organic mental syndrome in the elderly patient. In L. Bellak \& T.B. Karasu (Eds.), Geriatric psychiatry (pp. 77-121). New York: Grune \& Stratton.

Miller, E.N., Bing, E.G., Selnes, O.A., Wesch, J., \& Becker, J.T. (1993). The effects of sociodemographic factors on reaction time and speed of information processing. Journal of Clinical and Experimental Neuropsychology, 15, 66.

Murden, R.A., McRae, T.D., Kaner, S., \& Bucknam, M.E. (1991). Mini-Mental State exam scores vary with education in blacks and whites. Journal of the American Geriatrics Society, 39, $149-155$.

O'Carroll, R. (1995). The assessment of premorbid ability: A critical review. Neurocase, 1, 83-89.

O'Neill, J. (1990). The role of human capitol in earning differences between Black and White men. Journal of Economic Perspectives, 4, 25-45.

Overall, J.E. \& Levin, H.S. (1978). Correcting for cultural factors in evaluating intellectual deficit on the WAIS. Journal of Clinical Psychology, 34, 910-915.

Parasuraman, R. \& Haxby, J. (1993). Attention and brain function in Alzheimer's disease: A review. Neuropsychology, 7, 242-272.

Reynolds, C.R., Chastain, R.L., Kaufman, A.S., \& McLean, J.E. (1987). Demographic characteristics and IQ among adults: Analysis of the WAIS-R standardization sample as a function of the stratification variables. Journal of School Psychology, 23, 323-342.

Ripich, D.N., Carpenter, B., \& Ziol, E. (1997). Comparison of African-American and white persons with Alzheimer's disease on language measures. Neurology, 48, 781-783.

Roberts, R.J. \& Hamsher, K.D. (1984). Effects of minority status on facial recognition and naming performance. Journal of Clinical Psychology, 40, 539-545.
Rosen, W. (1981). The Rosen Drawing Test. Bronx, NY: Veterans Administration Medical Center.

Ross, T.P., Lichtenberg, P.A., \& Christensen, B.K. (1995). Normative data on the Boston Naming Test for elderly adults in a demographically diverse medical sample. Clinical Neuropsychologist, 9, 321-325.

Schmand, B., Geerlings, M.I., Jonker, C., \& Lindeboom, J. (1998). Reading ability as an estimator of premorbid intelligence: Does it remain stable in emergent dementia? Journal of Clinical and Experimental Neuropsychology, 20, 42-51.

Scruggs, T.E. \& Lifson, S.A. (1985). Current conceptions of testwiseness: Myths and realities. School Psychology Review, 14, 339-350.

Smith, J.P. (1984). Race and human capital. American Economic Review, 4, 685-698.

Smith, J.P. \& Welch, F. (1977). Black-White male wage ratios: 1960-1970. American Economic Review, 67, 323-328.

SPSS for Windows, Release 9.0.0 [Computer software]. (1998). Chicago: SPSS Incorporated.

Stern, Y., Andrews, H., Pittman, J., Sano, M., Tatemichi, T., Lantigua, R., \& Mayeux, R. (1992). Diagnosis of dementia in a heterogeneous population. Development of a neuropsychological paradigm-based diagnosis of dementia and quantified correction for the effects of education. Archives of Neurology, 49, 453-460.

Storandt, M., Stone, K., \& LaBarge E. (1995). Deficits in reading performance in very mild dementia of Alzheimer type. Neuropsychology, 9, 174-176.

Teresi, J.A., Golden, R.R., Cross, P., Gurland, B., Kleinman, M., \& Wilder, D. (1995). Item bias in cognitive screening measures: comparisons of elderly white, Afro-American, Hispanic and high and low education subgroups. Journal of Clinical Epidemiology, 48, 473-483.

United States Bureau of the Census. (1991). Census of population and housing 1990. Summary tape file 1, technical documentation prepared by the Bureau of the Census. Washington, DC: Bureau of the Census.

Unverzagt, F.W., Hall, K.S., Torke, A.M., \& Rediger, J.D. (1996). Effects of age, education and gender on CERAD neuropsychological test performance in an African American sample. Clinical Neuropsychologist, 10, 180-190.

Vincent, K.R. (1991). Black/White IQ differences: Does age make the difference? Journal of Clinical Psychology, 47, 266270.

Wechsler, D. (1981). Wechsler Adult Intelligence Scale-Revised. New York: The Psychological Corporation.

Welch, F. (1966). Measurement of the quality of education. American Economic Review, 56, 379-392.

Welch, F. (1973). Black-White differences in returns to schooling. American Economic Review, 63, 893-907.

Welsh, K.A., Fillenbaum, G., Wilkinson, W., Heyman, A., Mohs, R.C., Stern, Y., Harrell, L., Edland, S.D., \& Beekly, D. (1995). Neuropsychological test performance in African-American and white patients with Alzheimer's disease. Neurology, 45, 2207-2211.

Whitfield, K.E. \& Baker-Thomas, T. (1999). Individual differences in aging minorities. International Journal of Aging and Human Development, 48, 73-79.

Wilkinson, G.S. (1993). Wide Range Achievement Test 3Administration manual. Wilmington, DE: Jastak Associates, Inc. 